\title{
Increased peri- and post-elective cesarean section morbidity in women infected with human immunodeficiency virus-1: a case-controlled multicenter study
}

\author{
Olav Lapaire · Olivier Irion · Annemarie Koch-Holch • \\ Wolfgang Holzgreve Christoph Rudin • \\ Irène Hoesli • \\ The Swiss Mother and Child HIV Cohort Study \\ Received: 15 December 2005/ Accepted: 23 March 2006/Published online: 5 May 2006 \\ (C) Springer-Verlag 2006
}

\begin{abstract}
Objective: Although elective cesarean section (ECS) is the currently recommended modality for delivering women infected with the human immunodeficiency virus (HIV), historical evidence suggests that they are at higher risk of postoperative complications than noninfected women. Those risks have to be carefully balanced against the presumed minimal benefit of ECS, especially in the case of low viral load and high CD4 counts. We therefore compared the incidence and type of post-ECS complications in HIVinfected women, most with low viral loads and high CD4 cell counts, with those in matched noninfected women treated by the same surgical teams. Study design: A Swiss 8-center, prospective, matched casecontrol study compared minor and major post-ECS complication prevalence, hospital stay and confounding factors (surgeon experience) between HIV-infected and noninfected women. Results: Minor complications in the 53 matched pairs were eightfold more frequent overall in infected women. More frequent specific
\end{abstract}

O. Lapaire · W. Holzgreve · I. Hoesli

University Women's Hospital, Basel, Switzerland

O. Irion

University Women's Hospital, Geneva, Switzerland

A. Koch-Holch

University Women's Hospital, Zurich, Switzerland

C. Rudin

University Children's Hospital, Basel, Switzerland

I. Hoesli $(\bowtie)$

Universitätsspital Basel, Frauenklinik, Spitalstrasse 21, 4031 Basel, Switzerland

e-mail: HoesliI@uhbs.ch minor complications were anemia, blood loss and urinary tract infection. Yet the surgeons performing ECS in infected women were more experienced. Complications prolonged hospital stay in infected women. Major complication rates did not significantly differ between the groups. Conclusion: HIV-positive women have a higher risk of post-ECS morbidity, even with high CD4 counts and low viral load. Therefore, the blanket recommendation of ECS in HIV-infected women requires a review.

Keywords Maternal $\cdot$ Morbidity $\cdot \mathrm{HIV} \cdot$ Anemia Pregnancy

\section{Introduction}

Interventions markedly reduce the vertical transmission rate of the human immunodeficiency virus (HIV): by two-thirds (from 25 to $8 \%$ ) with zidovudine given orally during pregnancy, intravenously during delivery and orally to the newborn for 6 weeks [1], and by half with elective cesarean section (ECS) before rupture of the membranes and labor onset. The two interventions combined lower vertical transmission rates below $2 \%$ [2], i.e., to the level achieved with successful highly active antiretroviral treatment (HAART) during pregnancy. The blanket recommendation for ECS in HIV-infected women with a repeatedly undetectable viral load (viral RNA $<20$ copies/ml) is thus being questioned especially in Europe, where ECS has been the standard delivery modality in recent years. Its benefits in such favorable cases appear marginal: many ECS are required to prevent a single congenital HIV infection. Maternal morbidity is higher than in vaginal 
delivery, and mortality can be increased up to sixfold [3]. HIV-infected women may also be prone to increased post-ECS complication rates based on their underlying disease and/or immunosuppression [4-6]. Informed delivery modality counseling in women with viral loads below the limit of detection requires accurate quantification to balance the presumed minimal benefit of ECS against its risks. We therefore compared the incidence and type of post-ECS complications in HIV-infected women, most with low viral loads and high CD4 cell counts, with those in matched noninfected women treated by the same surgical teams.

\section{Materials and methods}

Pregnant HIV positive women, undergoing ECS in eight hospitals were recruited by the Swiss Mother and Child HIV Cohort Study (MoCHiV) [7]. Informed written consent was obtained in all cases. The women were matched at each center with HIV-negative patients selected as the next to undergo ECS after the infected index case. The noninclusion criteria were emergency cesarean section, rupture of the membranes, and multiple pregnancy. Matched-pair maternal postpartum complications were recorded by standardized case report forms, after hospital discharge by the supervising obstetrical team using consensus criteria for evaluating post-cesarean section morbidity [8]. The questionnaires were then assessed by the authors. The indication for ECS in infected women was the prevention of vertical transmission; in noninfected women the main indications were breech presentation and maternal request. All sections were performed before labor onset or membrane rupture, under spinal anesthesia, using a transperitoneal approach and transverse lower uterine segment incision. All infected women were offered combined antiretroviral treatment including a proteinase inhibitor and zidovudine as one of two nucleoside analogues. In one center, all patients received single-shot perioperative antibiotic prophylaxis $(2.2 \mathrm{~g}$ amoxicillin with clavulanic acid or, for those allergic to penicillin, clindamycin $600 \mathrm{mg}$ ) after cord clamping. All patients received low-molecular weight heparin during hospitalization. The following complications were classified as minor: anemia (hemoglobin $<100 \mathrm{~g} / \mathrm{l}$, hematocrit $<30 \%$ ), postpartum fever $\left(>38^{\circ} \mathrm{C}\right.$ for at least $24 \mathrm{~h}$ ), urinary tract infection [leukocyturia, bacteriuria ( $>10^{5}$ colonyforming units $/ \mathrm{ml}$ )], endometritis, wound infection, and hematoma. Major complications were pneumonia, thromboembolism, sepsis, peritonitis, diffuse intravascular coagulation, subileus/ileus, and anemia requiring blood transfusion (hemoglobin $<75 \mathrm{~g} / \mathrm{l}$, hematocrit $<$ $25 \%$ ). Complication rates and hospital stay were compared between matched pairs. Surgeon experience was documented as a potential confounding factor, classified into the following levels: resident, fellow, and attending surgeon.

\section{Statistical analysis}

Post-ECS complications in the infected group were analyzed with respect to risk factors (Centers for Disease Control classification, viral load, CD4 lymphocyte count, persistence of drug abuse). Fisher's exact test was used for categorical data, Student's $t$ test for normally distributed continuous data, and the MannWhitney $U$ test for ordinal data. All analyses were performed using SPSS 11.5.1 and a $P$ value $<0.05$. Based on a 1995 study in 156 women indicating a sixfold higher postoperative complication rate in HIVinfected women [4], a sample size of 140 women was required for a statistical power of $80 \%(P=0.05)$. However, after interim analysis confirmed the hypothesis of an increased postoperative complication rate in HIV-seropositive women, we terminated the study according to the protocol after including 106 women.

\section{Results}

Maternal age, gravidity, parity, and concomitant disease were similar in the 53 matched pairs (Table 1), as was operation time (Table 2). Current intravenous drug abuse rates were $44.2 \%$ in the infected group versus zero in the controls $(P<0.001)$. Immunological status (CD4 lymphocyte count) and viral load data were available in $94.3 \%(50 / 53)$ of infected patients (Table 1). In 44.2\% (23/53), infection was acquired by intravenous drug use, and in $55.7 \%(29 / 53)$ by heterosexual contact; the source was unknown in the remaining case. Mean gestational age at delivery was shorter in the infected group [37.9 weeks (SD 1.97) vs. 39.0 weeks (SD 1.44) in the controls: $P<0.001$ ]. Severe preeclampsia at 26 weeks in one infected case and pregnancy-induced hypertension at 32 weeks in another led to surgical delivery before 37 weeks of gestation; in all other cases, ECS was performed after 37 weeks of gestation. No instance of neonatal HIV infection occurred during the study. In the infected group $86.8 \%(46 / 53)$ received antibiotic prophylaxis versus $62.3 \%(33 / 53)$ of the controls $(P<0.04)$. ECS was performed by residents in $22.6 \%(12 / 53)$ of the infected group versus in $60.4 \%(32 / 53)$ of controls, by 
Table 1 Population demographic, obstetric and virologic characteristics

\begin{tabular}{|c|c|c|c|}
\hline \multirow[t]{2}{*}{ Variable } & \multicolumn{2}{|l|}{ HIV status } & \multirow[t]{2}{*}{$P$} \\
\hline & Positive & Negative & \\
\hline Age (years) & $32.55(24-41)$ & $31.00(18-40)$ & $0.10 *$ \\
\hline Parity & $1.38(0-4)$ & $1.58(1-4)$ & $0.20 * *$ \\
\hline Gravidity & $2.12(1-5)$ & $2.04(1-5)$ & $0.59 * *$ \\
\hline $\begin{array}{l}\text { Gestational age } \\
\text { at delivery (week) }\end{array}$ & $37.87(26-40)$ & $39.00(32-42)$ & $0.001 * *$ \\
\hline $\begin{array}{l}\text { Concomitant } \\
\quad \text { disease }^{\mathrm{a}}[\%(n / N)]\end{array}$ & $9.4(5 / 53)$ & $15(8 / 53)$ & $0.39 * * *$ \\
\hline \multicolumn{4}{|l|}{ CD4 count } \\
\hline $200-499 \mathrm{~mm}^{-3}$ & 21 & & \\
\hline$<200 \mathrm{~mm}^{-3}$ & 5 & & \\
\hline Unknown & 3 & & \\
\hline \multicolumn{4}{|l|}{ Viral load } \\
\hline$<100(\log <2)$ & 36 & & \\
\hline $100-10,000(\log 2-4)$ & 11 & & \\
\hline $10,000(\log >4)$ & 2 & & \\
\hline Unknown & 3 & & \\
\hline
\end{tabular}

Mean (range)

$* t$ test, **Mann-Whitney $U$ test, ${ }^{* * *}$ Fisher's exact test

${ }^{a}$ Gestational diabetes, hepatitis $\mathrm{C}$ virus infection, epilepsy and current intravenous drug abuse

fellows in $37.7 \%(20 / 53)$ versus $11.3 \%(6 / 53)$, and by attending surgeons in $39.6 \%(21 / 53)$ versus $28.3 \%$ (15/53), respectively $(P<0.001)$. Postoperative recovery was uncomplicated in $41.5 \%(22 / 53)$ of the HIV group versus $84.9 \%(45 / 53)$ of controls. Minor complications were eightfold more frequent [relative risk (RR): 7.94; 95\% confidence interval (CI): 3.1-20.0; $P<0.01]$. Postoperative anemia occurred in $49 \%$ (26/53) of the HIV group versus 9.4\% (5/53) of controls (RR: 9.24; CI: 3.2-26.9; $P<0.001$ ). Mean estimated intraoperative blood loss was higher in anemic than in non-anemic HIV patients [652 $\mathrm{ml}$ (SD $113.6 \mathrm{ml}$ ) vs. $552 \mathrm{ml}(\mathrm{SD} 78.1 \mathrm{ml}) ; P<0.01]$. Urinary tract infection was more frequent in the HIV group [11.3\% (6/53) vs. 3.7\% (2/53); RR: 2.7; CI: 0.5-14.4; $P<0.05]$. There were two cases of fever in the HIV group versus none in the controls, one postoperative hematoma per group, and one wound dehiscence in the HIV group.
Major complications were recorded in $5.6 \%(3 / 53)$ of the study group, versus none in the controls, including two cases of pneumonia and one of thromboembolism, $P=0.38$. Hospital stay was significantly longer in the HIV group $(P<0.001$, Table 2$)$.

\section{Comment}

Following several reports suggesting a significant increase in post-ECS morbidity in HIV-infected women with different population characteristics (Table 3) [4-6, 9-13], we found an eightfold increase in overall minor complications, and a fivefold increase in postoperative anemia. An important feature of our study is that viral load data were available in $94 \%$ of our patients versus in only $27 \%(26 / 97)$ in a comparable previous publication [6]. All our patients received HAART and over $60 \%$ had a non-detectable viral load: these rates are also higher than those reported elsewhere. In addition, $58 \%$ received perioperative antibiotic prophylaxis. Nevertheless, urinary tract infections were 2.7-fold more frequent than in noninfected women, suggesting an increased risk of postoperative infection in HIVseropositive patients. Therefore, we agree with Grubert et al. [14] that the standard antibiotic prophylaxis used in the nonimmunocompromised obstetric population may be insufficient to prevent infections in HIVseropositive patients. Pairs were matched at each center to reduce the bias of different operative and postoperative schemes. In our study, ECS in the HIV group was performed by the more experienced surgeons. Since this ought to have optimized postoperative outcome, it further emphasizes the results. Our finding of significantly higher blood loss in HIV-seropositive women contradicts two earlier studies $[6,15]$ but confirms a recent report [10] which also showed higher blood loss in previously anemic women. Our study suggests that postoperative anemia tends to result from markedly higher blood loss rather than from slow postoperative bleeding or preoperative chronic anemia [16]. This is in contrast to the hypothesis that

Table 2 HIV status and operation time, blood loss and hospital stay

\begin{tabular}{lccc}
\hline & HIV status & & \\
\cline { 2 - 3 } & Positive & Negative & \\
\hline Operation time (min) & $37.5(18-55)$ & $36.4(17-57)$ & $0.54 *$ \\
Blood loss (ml, estimated) & $601.9(400-1,000)$ & $479.3(200-1,000)$ & $<0.001^{*}$ \\
Hospital stay (days) & $9.4(6-49)$ & $6.5(4-8)$ & $<0.001 * *$ \\
\hline
\end{tabular}

Mean (range)

$* t$ test, **Mann-Whitney $U$ test 
Table 3 Historical post-elective cesarean section complications in HIV seropositive women

\begin{tabular}{|c|c|c|c|c|}
\hline \multirow{2}{*}{$\begin{array}{l}\text { Study } \\
\text { (first author) }\end{array}$} & \multirow{2}{*}{$\begin{array}{l}\text { Patients } \\
(N)\end{array}$} & \multicolumn{2}{|l|}{ Complications } & \multirow{2}{*}{$\begin{array}{l}\text { Hospital } \\
\text { stay }^{\mathrm{a}} \text { (days) }\end{array}$} \\
\hline & & Major & Minor & \\
\hline Fiore [10] & 158 & OR 5.1 (CI $0.58-48.0)$, NS & OR 1.51 (CI 1.22-2.41) & $7.4(3.7)$ \\
\hline Marcollet [9] & 109 & $\begin{array}{l}\text { OR } 1.85 \text { (any postpartum morbidity) } \\
\text { (CI } 1.00-3.39)\end{array}$ & & $6.5(3.5)$ \\
\hline Grubert [14] & 62 & OR 3.7 (CI 1.4-9.6) & OR 1.3 (CI $0.3-4.9), \mathrm{NS}$ & \\
\hline Rodriguez [6] & 86 & OR 2.84 (CI $0.66-14.06), \mathrm{NS}$ & OR 2.73 (CI $1.40-5.33)$ & \\
\hline Urbani [13] & $7^{\mathrm{b}}$ & & & $4.2(2-9)$ \\
\hline Vimercati [12] & 28 & $P<0.9$ versus controls & $P<0.03$ versus controls & \\
\hline Maiques-Montesinos [5] & 18 & $P<0.003$ versus controls & $P<0.00001$ versus controls & $8.0(7-45)$ \\
\hline Semprini [4] & 156 & OR $6.0($ CI $0.9-38.5), \mathrm{NS}$ & OR 3.1 (CI 1.3-7.6) & \\
\hline
\end{tabular}

CI 95\% confidence interval, $O R$ odds ratio, $N S$ nonsignificant

${ }^{\mathrm{a}}$ Mean (range)

${ }^{\mathrm{b}}$ Emergency cesarean sections: 52/59

preoperative anemia due to antiretroviral therapy accounts for the higher frequency of blood transfusion [17]. Currently, the higher intraoperative blood loss may be more significant than viral or drug-induced anemia. Indeed, current reports suggest that anemia may even improve with HAART [18]. The clinical relevance of our finding lies in the previously documented association between anemia and reduced survival $[19,20]$. In addition, anemia may lower quality of life in HIV-seropositive patients [21]. Overall, more major complications were observed in the HIV-seropositive groups, reaching no statistical significance, presumably due to the sample size. The increased postoperative complication rate, which is also expressed in a marked prolongation of the hospital stay, further worsens not only patient's quality of life, but also the financial burden on the healthcare system. A potential weakness of our study was that it did not achieve its intended statistical power. Further limitations are the absence of preoperative hemoglobin levels or platelet and coagulation factor data, which could have had a bearing on intraoperative blood loss. However, none of these factors is likely to have a significant impact on the results, in particular, as our primary focus was the association between HIV and postoperative morbidity. In conclusion, our data indicate that the current blanket recommendation of ECS in HIV-seropositive patients requires review, especially in those with low/undetectable viral loads and high CD4 counts, as a result of HAART.

Acknowledgement We thank Anette Kratzer, M.D., for initiating and collecting part of the data, Andy Schötzau for the statistical analysis, and Linda Herberich, M.D., for proof reading the manuscript. We also thank the Swiss hospitals of Aarau, Bern, Chur, Freiburg, Liestal, St. Gallen, Winterthur, and Zurich for their support. The Swiss HIV Cohort Study is financed by the Swiss National Science Foundation (grant 3347-069366).

\section{Appendix}

The Swiss HIV Cohort Study (SHCS) and the Swiss Mother and Child HIV Study (MoCHiV) members: Manuel Battegay, Enos Bernasconi, Kurt Biedermann, Jürg Böni, Heiner Bucher, Philippe Bürgisser, Sandro Cattacin, M. Cavassini, Rolf Dubs, Matthias Egger, Luigia Elzi, Peter Erb, Karin Fantelli, Marek Fischer, Markus Flepp, Adriano Fontana, Patrick Francioli (SHCS President), Hansjakob Furrer (SHCS Clinical and Laboratory Committee Chairman), Meri Gorgievski, Huldrych Günthard, Bernard Hirschel, Irène Hösli, Christian Kahlert, Laurent Kaiser, Urs Karrer, Olivia Keiser, Christian Kind, Thomas Klimkait, Bruno Ledergerber, Gladys Martinetti, Begona Martinez de Tejada, Nicolas Müller, David Nadal, Milos Opravil, Fred Paccaud, Giuseppe Pantaleo, Luc Perrin, Martin Rickenbach, Christoph Rudin (Chairman, MoChiV), Patrick Schmid, Detlev Schultz̈e, Jörg Schüpbach, Roberto Speck, Patrick Taffé, Philip Tarr, Amalio Telenti, Alexandra Trkola, Pietro Vernazza (SHCS Scientific Board Chairman), Rainer Weber, Sabine Yerly.

\section{References}

1. Connor EM, Sperling RS, Gelber R, Gelber R, Kiselev P, Scott G, O'Sullivan MJ et al (1994) Reduction of maternalinfant transmission of human immunodeficiency virus type 1 with zidovudine treatment. Pediatric AIDS Clinical Trials Group Protocol 076 Study Group. N Engl J Med 331:11731180

2. The European Mode of Delivery Collaboration (1999) Elective caesarean-section versus vaginal delivery in prevention of vertical HIV-1 transmission: a randomised clinical trial. Lancet 53:1035-1039

3. Hall MH, Bewley S (1999) Maternal mortality and the mode of delivery [letter]. Lancet 354:776 
4. Semprini AE, Castagna C, Ravizza M, Fiore S, Savasi V, Muggiasca ML, Grossi E et al (1995) The incidence of complications after cesarean section in $156 \mathrm{HIV}$-positive women. AIDS 9:913-917

5. Maiques-Montesinos V, Cervera-Sanchez J, Bellver-Pradas J, Abad-Carrascosa A, Serra-Serra V (1999) Post-cesarean section morbidity in HIV positive women. Acta Obstet Gynecol Scand 78:789-792

6. Rodriguez EJ, Spann C, Jamieson D, Lindsay M (2001) Postoperative morbidity associated with cesarean delivery among human immunodeficiency virus-seropositive women. Am J Obstet Gynecol 184:1108-1111

7. Kind C, Rudin C, Siegrist CA, Wyler CA, Biedermann K, Lauper U, Irion O, Schupbach J, Nadal D (1998) Prevention of vertical HIV transmission: additive protective effect of elective caesarean section and zidovudine prophylaxis. Swiss Neonatal HIV study Group. AIDS 12:205-210

8. NIH Consensus Development Task Force statement on Cesarean Childbirth (1981) Am J Obstet Gynecol 139:902909

9. Marcollet A, Goffinet F, Firtion G, Pannier E, Le Bret T, Brival ML, Mandelbrot L (2002) Differences in postpartum morbidity in women who are infected with the human immunodeficiency virus after elective cesarean delivery, emergency cesarean delivery, or vaginal delivery. Am J Obstet Gynecol 186:784-789

10. Fiore S, Newell ML, Thorne C for the European HIV in Obstetrics Group (2004) Higher rates of post-partum complications in HIV-infected than in uninfected women irrespective of mode of delivery. AIDS 18:933-988

11. Ferrero S, Bentivoglio G (2003) Postoperative complications after cesarean section in HIV infected women. Arch Gynecol Obstet 268:268-273

12. Vimercati A, Greco P, Loverro G, Lopalco PL, Pansini V, Selvaggi L (2000) Maternal complications after caesarean section in HIV infected women. Eur J Obstet Gynecol Reprod Biol 90:73-76
13. Urbani G, de Vries MM, Cronje HS, Niemand I, Bam RH, Beyer E (2001) Complications associated with cesarean section in HIV-infected patients. Int J Gynaecol Obstet 74:915

14. Grubert T, Reindell D, Kästner R, Belohradsky BH, Gurtler L, Stauber M, Dathe O (2002) Rates of postoperative complications among human immunodeficiency virus-infected women who have undergone obstetric and gynecologic surgical procedures. Clin Infect Dis 34:822-830

15. Watts DH, Lambert JS, Stiehm ER, Bethel J, Whitehouse J, Fowler MG, Read J (2000) Complications according to mode of delivery among human immunodeficiency virus-infected women with CD4 lymphocyte counts $<500 / \mu$ l. Am J Obstet Gynecol 183:100-107

16. Shander A, Knight K, Thurer R, Adamson J, Spence R (2004) Prevalence and outcomes of anemia in surgery: a systematic review of the literature. Am J Med 116:58S-69S

17. Grubert T, Reindell D, Kästner R, Lutz-Friedrich R, Belohradsky BH, Dathe O (1999) Complications after cesarean section in HIV-1-infected women not taking antiretroviral treatment. Lancet 354:1612-1613

18. Semba RD, Shah N, Klein RS, Mayer KH, Schuman P, Vlahov D (Human Immunodeficiency Virus Epidemiology Research Study Group) (2002) Prevalence and cumulative incidence of and risk factors for anemia in a multicenter cohort study of human immunodeficiency virus-infected and -uninfected women. Clin Infect Dis 15:260-266

19. Moore RD, Keruly JC, Chaisson RE (1998) Anemia and survival in HIV infection. J Acquir Immune Defic Syndr Hum Retrovirol 19:29-33

20. Belperio PS, Rhew DC (2004) Prevalence and outcomes of anemia in individuals with human immunodeficiency virus: a systematic review of the literature. Am J Med 116(Suppl 7A):27S-43S

21. Abrams DI, Steinhart C, Frascino R (2000) Epoetin alfa therapy for anaemia in HIV-infected patients: impact on quality of life. Int J STD AIDS 11:659-665 